Eventos 



\title{
EQUIPE INTERDISCIPLINAR FRENTE AO PACIENTE TERMINAL ${ }^{\star}$
}

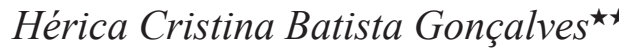 \\ Hugo Leonardo Rodrigues Soares $\star \star \star ~$ \\ Flávio Augusto Prado Vasques ${ }^{\star \star \star \star}$
}

\section{Palavras-chaves: Paciente terminal. Equipe interdisciplinar. Psicologia Hospitalar}

INTRODUÇÃO: O trabalho com pacientes terminais está se configurando como uma área em que os profissionais do hospital podem desenvolver uma atividade muito importante, dentro de uma linha de valorização do ser humano e da pessoa que está acometida de uma doença grave. A terminalidade relaciona-se aos momentos finais, quando o tratamento já não implica cura e sim o alívio de sintomas e a preservação da vida. É importante, segundo esse autor, um tratamento na esfera psicossocial, além da área médica, num trabalho integrado. A importância do trabalho com pacientes terminais surge de um ponto de vista sociológico, do hospital como instituição despersonalizante que não é, por definição, estabelecido para suprir as necessidades de pessoas cujas condições psicológicas estão além da capacidade hospitalar de socorro; esses pacientes representam um fracasso da instituição no seu papel de apoio à vida, não há nada nesse sistema que supra a carência do espírito humano quando o corpo necessita de cuidados.

OBJETIVOS: A equipe interdisciplinar atuante no hospital é envolvida nos esforços para se tratar com dignidade o paciente, considerando-o nos seus aspectos biológicos, sociais, psicológicos e espirituais. A interdisciplinaridade deve ir além da mera justaposição de disciplinas. Preconiza-se o diálogo permanente com outros conhecimentos

METODOLOGIA: Este trabalho se propôs a realizar uma revisão na literatura sobre a atuação da equipe interdisciplinar frente ao paciente terminal, observando-se os sentimentos e as dificuldades enfrentadas pela equipe no manejo destes pacientes.

RESULTADOS E CONCLUSÕES: O Psicólogo juntamente a equipe médica em geral, atuará no processo de adoecimento que traz à vida do indivíduo profundas mudanças ligadas tanto à sua capacidade produtiva, quanto no ambien-

* Trabalho apresentado na $29^{\text {a }}$ Semana Científica da Faculdade de Medicina da UFF, realizada em 30 de novembro e 1 de dezembro de 2006, no Hospital Universitário Antônio Pedro, Niterói, Rio de Janeiro.

$\star \star$ Graduanda em Psicologia pela Universidade Federal Fluminense

$\star \star \star$ Médico Graduado pela Universidade Federal Fluminense

$\star \star \star \star$ Orientador e Professor Adjunto do Departamento Materno-Infantil - Faculdade de Medicina. Doutor em Obstetrícia pela Escola Paulista de Medicina - UNIFESP. Endereço: Departamento Materno-Infantil - Faculdade de Medicina - Hospital Universitário Antônio Pedro (HUAP) Rua Marquês do Paraná, 303 - Centro - Niterói - RJ. CEP: 24.303-900

E-mail: pradovasques@yahoo.com.br 
te familiar, trazendo não só limitações físicas, mas também sociais e psíquicas. O Psicólogo Hospitalar tem um papel fundamental no trabalho com pacientes terminais, pois além dar o suporte ao indivíduo no contexto de crise em que se encontra, devido a essa "parada" do seu ritmo cotidiano, também abrange na sua atuação, a função de esclarecer, orientar o paciente e seus familiares, sobre as conseqüências geradas pelo adoecimento e proporcionar a estes, uma reorganização e a readaptação ao seu meio psicossocial, sendo importante entender que este paciente irá vivenciar sua doença de forma única, individual. É importante assinalar que o processo psicoterápico com pacientes terminais não tem como meta à cura de processos somáticos e não entra no lugar dos tratamentos médicos. Também não tem como objetivo acalmar ou "amansar" o paciente, para que ele se torne mais dócil, não atrapalhe o médico com suas exigências, sendo este um pedido freqüente aos psicólogos hospitalares. Sendo assim, o psicólogo não deve entrar no vácuo deixado pelo médico, ou seja, substituí-lo na relação com o paciente ou servir como intermediário dessa relação. $\mathrm{O}$ médico tem seu lugar legitimado no contato com o paciente e, para não fugir ao confronto com situações que são extremamente difíceis e que podem surgir na relação com um paciente terminal, tem por obrigação lidar com seus próprios conteúdos internos. 